\title{
Roadbed Subsidence Mechanisms under the Driven of Penetration-Soak Coupling
}

\author{
Hongkai Chen, Dan Liang \\ Institute of Geotechnical Engineering, Chongqing Jiaotong University, Chongqing, China \\ Email: 1043601266@qq.com
}

How to cite this paper: Chen, H.K. and Liang, D. (2017) Roadbed Subsidence Mechanisms under the Driven of PenetrationSoak Coupling. Journal of Geoscience and Environment Protection, 5, 97-106. https://doi.org/10.4236/gep.2017.52008

Received: October 13, 2016 Accepted: February 7, 2017 Published: February 14, 2017

\begin{abstract}
Roadbed subsidence is one of the main types of highway flood damage, the periodic fluctuation of the river water level and the softening of the subgrade soils by the river water immersion for a long time are the main inducement factors of the subgrade subsidence. Based on the theory of absorbing water infiltration in unsaturated soil, calculation formula of dynamic stability coefficient of subgrade is established by using the Swedish arc method. Example analysis shows that, soil roadbed suffers the water permeability-soak, roadbed's stability reduce with the time, and leads to roadbed subsidence. Research results for improving roadbed subsidence water logging mechanism understanding level have a positive meaning.
\end{abstract}

\section{Keywords}

Road Engineering, Subsidence Mechanism, Penetration-Soaking

Coupling, Soil Roadbed

\section{Introduction}

At present, in the remote mountainous areas of western China, the connection between the villages and towns is still the main road along the river, roadbed stability directly affects the safety of vehicles and pedestrians in the past. Roadbed damage and water are closely related to the river by the long-term infiltration in the infiltration of roadbed softening gradually, the soil strength and carrying capacity to reduce, easily lead to subsidence or slump collapse roadbed.

Zhao Yu-kun et al. [1] on the lower reaches of the Yellow River section of a dike under flood conditions for long-term immersion conditions of the soil strength index test; Tang Xiaosong [2] took two kinds of water immersion test. The results show that the bearing capacity of the crushed-stone foundation can be reduced by about $30 \%$ under the long-term immersion of the reservoir water. 
He Xiaoying et al. [3] used polycrystalline X-ray. The results showed that the periodic leaching of the gravelly soil caused by the long-term immersion and cyclic immersion is the important factor to the deterioration of soil structure and strength.

According to above-mentioned research results, the two processes of soak softening and water absorption of the Roadbed are studied independently. The literatures on the study of water absorption, softening and dynamic stability of embankment are rarely seen. Based on the above-mentioned related Roadbed infiltration and soaking Softening research results, through the roadbed infiltration-immersion simplified model, established a set of roadbed dynamic stability analysis method, the method further enriched along the river roadbed subsidence formation mechanism theory, research results for the promotion of roadbed subsidence water damage mechanism understanding level Positive meaning. Deng Xin [4] and so on through the experimental study of Yunnan red soil under long immersion in the shear strength of damage characteristics. In the aspect of water absorption of Roadbed, Zhang Zhiqing [5] obtained the relation between infiltration flow and time and longitudinal and transverse permeability profile through the water management characteristics, water infiltration and the development rule of collapsibility of loess Roadbed; Li et al. [6] Huang Yu et al. [7] carried out a series of experiments on the seepage in situ in three kinds of loess soils. The results show that the water infiltration rate of the unsaturated soils is high, Li Yongle et al. [8] used unsaturated soil triaxial apparatus made by ourselves to study the unsaturated soils of the Yellow River levee. The unsaturated soils of the Yellow River embankment and the relationship between confining pressure and water content and permeability coefficient was obtained. Liu Wenhua [9] studied the seepage characteristics of unsaturated soil Roadbed under different rainfall infiltration conditions.

\section{Submerged İnfiltration-Soaking and Softening Mechanism}

Under normal circumstances, Roadbed damage is mostly caused by water, water is to determine the stability of Roadbed slope stability of the most important external factors. At the macro level, because the road is close to the river, the river water level rises rapidly in the flood season, the foot of the riverbed is submerged by the water, the riverbed will be infiltrated a lot of water, so that the lower part of the roadbed is saturated, after the flood season, the river water level drops rapidly, In the process of water seepage force to reduce, the effective increase in soil gravity, while the resulting infiltration is not conducive to the stability of Roadbed slope, followed by heavy rainfall, a large number of Surface water infiltration to the roadbed slope or cracks, resulting in increased slope weight, is not conducive to the stability of the roadbed.

On the microscopic level, due to repeated rise and fall of river water level, recurrent seepage occurs in the embankment, repeated seepage of roadbed water body will produce leaching effect, take away small particles in the soil and embankment erosion phenomenon. Secondly, when the water body immersed in 
the natural unsaturated roadbed soil will lead to the original soil particles cementation between the destruction of soil particles on the surface of the water film thickening, so that the matrix between the matrix to reduce suction, Weakening the soil cohesion and shear strength, that is, the performance of soil soaking softening phenomenon [10], when the roadbed at the bottom of the soil after immersion softening, roadbed slope will experience creep, affecting the road when the performance of the road surface of the uneven deep or roadbed instability.

\section{Calculation of Infiltration of Roadbed}

\subsection{Roadbed Simplification Model}

The roadbed along the river is mainly divided into two types: excavated roadbed and filled roadbed. Only the above two types of soil Roadbed are used to analyze and calculate the roadbed subsidence. The soil Roadbed is mainly composed of gravelly soil or miscellaneous fill soil. The soil structure is loose and permeable, and the Roadbed soil will soften and deform when subjected to long-term infiltration and soaking. Most of the natural soil Roadbed along the river road is filled in the embankment is the original slope, if the excavation of the roadbed is sitting on a stable bedrock above. In order to facilitate the study, this paper will simplify the natural soil roadbed model shown in Figure 1, the roadbed at the bottom and the back wall are impermeable layer, the road is a single two-lane, the width of the top surface of the embankment is $b$, the bottom width is $B$, the slope angle is $\theta$, Roadbed side of the river, river water level $h_{w}$

\subsection{Basic Assumptions}

1) The average annual variation of river water level is small, and it is calculated as the fixed water level;

2) Unsaturated soil along the riverbed, the river occurred in the soil is unsaturated water infiltration and infiltration direction of the horizontal direction;

3) Roadbed is homogeneous soil, its density and water content and other physical and mechanical parameters in the entire roadbed evenly distributed;

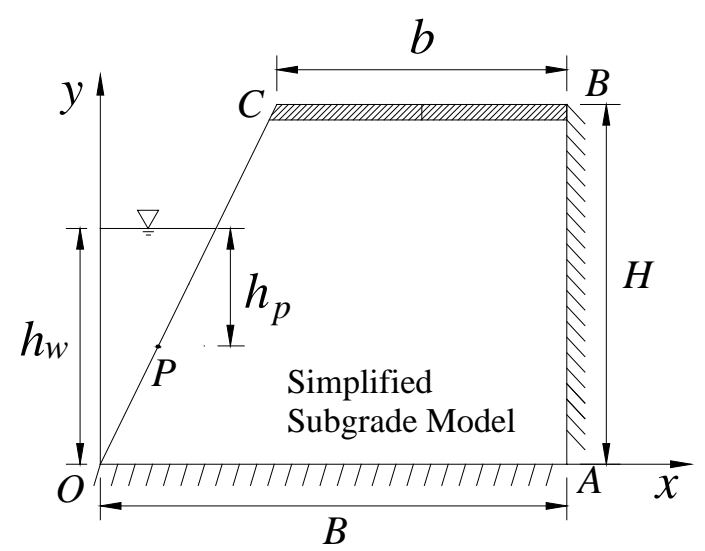

Figure 1. Simplified model of roadbed along river. 


\subsection{Unsaturated Roadbed İnfiltration İnfiltration Front}

In the natural state, the excavated or filled Roadbed soils are mostly non-saturated and the unsaturated seepage occurs in the Roadbed soil. The relevant scholars have done a lot of research on the unsaturated seepage in the soil. Sun Dasong [11], Burdine NT [12] and Li Yongle [8] and others found that the permeability of unsaturated soil in the unsaturated soil properties still meet the Darcy law, and unsaturated soil water absorption of the average rate can be expressed as:

$$
V=k_{u s} \frac{d h}{d s}
$$

among them, $V$ is the average velocity of the water in the pores $/ \mathrm{md}^{-1} ; k_{u s}$ is the permeability coefficient of unsaturated Soil $/ \mathrm{md}^{-1}$; $d h$ is the head height difference $/ \mathrm{m} ; d s$ is the water seepage path $/ \mathrm{m}$

According to the formula (1), it can be seen that the permeation rate of each point is linear with the hydraulic gradient. After the unsaturated roadbed is exposed to the river water, rapid water absorption occurs first, then the saturated infiltration is started, and the process of water absorption and infiltration is repeated to infiltrate into the Roadbed. The infiltration front is arc-shaped, as shown in Figure 2, at different times corresponding to different infiltration front, with the passage of time if the road surface slope of the initial head of the different, resulting in different elevation of the water flow rate of the average difference exists, Roadbed will not damage the infiltration front will eventually be flush with the water level, then the roadbed in the water and soil to achieve a balanced state, the entire lower embankment all immersed in the river.

In order to further study the unsaturated infiltration characteristics of the water flow in Roadbed soil, based on the simplified Roadbed model, the slope axis of the embankment is taken as the origin to establish the coordinate axis xoy, slope any point $P\left(x_{p}, y_{p}\right)$ in the water level below the roadbed, Take a wooden strip to do the study of water absorption characteristics along the horizontal direction, As shown in Figure 3, when the river water infiltration to Figure 4

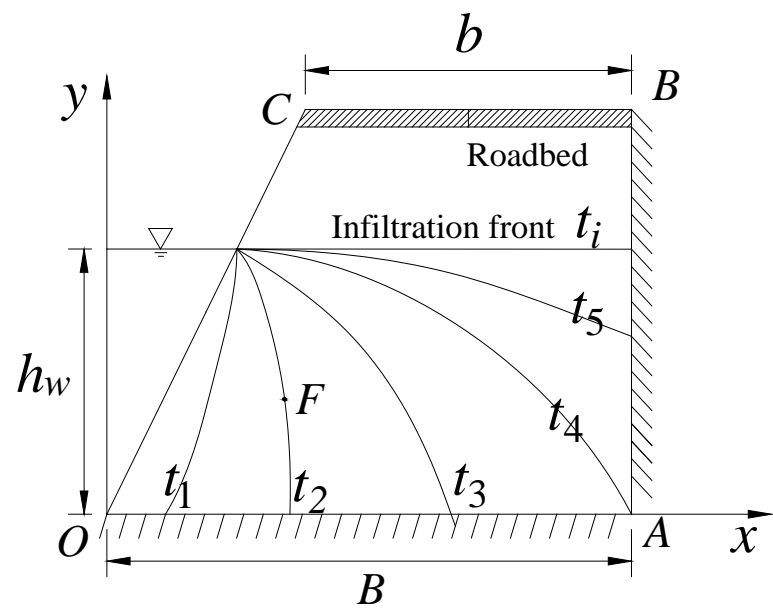

Figure 2. Developmental map of Roadbed infiltration front. 


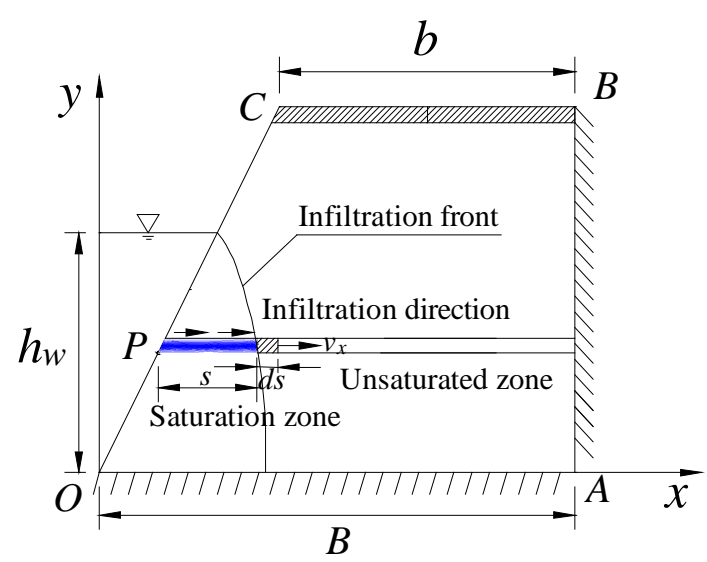

Figure 3. Sketch map of subsoil water absorption calculation.

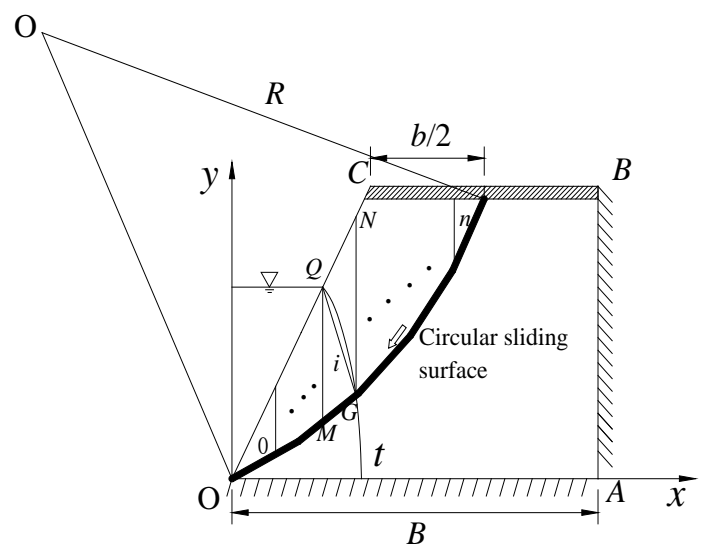

Figure 4. The model of roadbed stability calculation.

shows the set, the front to take a length of the micro- $d s$ body, let the water infiltration of the micro-unit time spent $d t$, you can get

$$
v_{x} d t=d s
$$

among them, $V_{x}$ is the infiltration front seepage velocity $/ \mathrm{ms}^{-1}$

The hydraulic gradient is replaced by the head difference, which is, substituting Equation (1) into Equation (2)

$$
k_{u s} \frac{h_{w p}}{s} d t=d s
$$

among them, $h_{w p}$ is the head height of $\mathrm{P}$ point $/ \mathrm{m}, h_{w p}=h_{w}-y_{p} ; s$ is the length of seepage path $/ \mathrm{m}$, the remaining variables are the same as above.

After the separation of variables (3) integration, the relationship between the infiltration distance and the seepage time of the water flow at different head height can be obtained

$$
s=\sqrt{2 k_{u s}\left(h_{w}-y_{p}\right) t}
$$

In the infiltration of the front to take any point $F(x, y)$ at $\mathrm{t}$ time, as shown in Fig, therefore this point must be satisfied 


$$
s+y \cot \theta=x
$$

Substituting Equation (4) into Equation (5), we can get the expression of infiltration front function in Roadbed soil at any time

$$
x=y \cot \theta+\sqrt{2 k_{u s}\left(h_{w}-y\right) t}
$$

When the river infiltrates point A on the model map, the infiltration front is no longer advancing deep into the embankment, Turn to the upper part of the development, and ultimately with the river water flush, Therefore, Equation (6) can only be used to describe the infiltration front.

\section{Roadbed Stability Calculation}

It is found that the subsidence of the soil Roadbed along the river is similar to that of the rainfall-induced landslide, and the sliding surface is usually circular arc. Based on the circular slip method, the Swedish slit method is used to analyze the flooding soil Roadbed stability analysis. Suppose the Roadbed is damaged when the sliding surface trailing edge in the highway center line. As shown in Figure 4, Assumptions the center of the circular sliding surface is $O\left(x_{0}, y_{0}\right)$, radius is $R$, With the infiltration of the t-time frontal cross at the point $G\left(x_{g}, y_{g}\right)$, the coordinates of point $G$ should be satisfied

$$
\left\{\begin{array}{l}
x_{g}=y_{g} \cot \theta+\sqrt{2 k_{u s}\left(h_{w}-y_{g}\right) t} \\
\left(x_{g}-x_{0}\right)^{2}+\left(y_{g}-y_{0}\right)^{2}=R^{2}
\end{array}\right.
$$

where the center coordinates can be obtained from the following equations

$$
\left\{\begin{array}{l}
x_{0}{ }^{2}+y_{0}{ }^{2}=R^{2} \\
\left(y_{0}-H\right)^{2}+\left(x_{0}-b / 2-H \cos \theta\right)^{2}=R^{2}
\end{array}\right.
$$

Combining (7) and (8), the coordinates of the intersection $\mathrm{G}$ can be obtained.

For the convenience of calculation, using the $\mathrm{Q}$ and $\mathrm{G}$ points as the corners of the bars, when dividing a bar, and simplifying the QG segment infiltration front, as shown in Figure, taking into account the Roadbed soil in the water infiltration-soaked softening after the main physical and mechanical parameters will be deteriorated. Therefore, the soil parameter deterioration coefficient $\eta$ is introduced, According to the Mohr-Coulomb criterion of saturated soil, Shear strength of soil can be obtained

$$
\tau_{f}=\eta c+\sigma^{\prime} \tan (\eta \phi)
$$

among them, $\tau_{f}$ is the Shear strength of soil/kpa; $c$ is the Cohesion of natural soil/kpa; $\sigma$ is the Effective stress/kpa; $\varphi$ is the Friction angle of natural soil/

For unsaturated soils, there is matrix suction in the soil, Shear strength characteristics and saturated soil are quite different, Chen Jingyu and Fredlund D. G [13] based on the previous research results summarize the practice of unsaturated soil shear strength of the expression

$$
\tau_{f}=c+\sigma \tan \phi+\tau_{s}
$$

among them, $\sigma$ is the Total stress of soil/kpa; $\tau_{s}$ is the Equivalent Unsaturated 
Soil Adsorption Strength/kpa, It is linearly related to the matrix suction of unsaturated soils and can be obtained experimentally. The other variables are the same as above.

In this paper, the sliding surface below $G$ point is calculated using the saturated soil shear strength formula, $G$ point above, the use of unsaturated soil strength formula for roadbed stability calculation. As shown in Figure 5, taking the block QMGR for stress analysis, Swedish striping does not take into account the force between the bars.

Bar Gravity: $W_{i}=W_{i s}+W_{i u}$

Bar drop force: $F_{i}=W_{i} \sin \alpha_{i}$

Slippage resistance:

$T_{i}=\left(W_{i} \cos \alpha_{i}-u_{i} l_{i}\right) \tan \eta \varphi^{\prime}+\eta \dot{c}_{i}^{\prime} I_{i}$ (Saturated belt sliding surface)

$T_{i}=W_{i} \cos \alpha_{i} \tan \varphi+c_{i} l_{i}+\tau_{s} l_{i}$ (Unsaturated belt sliding surface)

among them, $W_{i s}$ is the Saturated soil gravity/KN; $W_{i u}$ is the Unsaturated soil gravity $/ \mathrm{KN} ; l_{i}$ is the Length of block slip surface $/ \mathrm{m} ; \alpha_{i}$ is the angle between the tangent of the slide surface and the horizontal line $/^{\circ}$.

In addition to the above load, the top of the roadbed is also subject to the vehicle load, the vehicle load can be superimposed on the weight of the bar on the calculation, the size of the load according to the relevant level of highway standards. Furthermore, the slip coefficient of the Roadbed soil can be calculated by using the ratio of the anti-sliding force and the sliding moment to the center of the soil.

\section{Case Study}

Taking the subsidence section of the secondary road in Pug County, Sichuan Province as an example, The section is filled roadbed, The high roadbed is $H=$ $4.6 \mathrm{~m}$, The width of the road is $b=6 \mathrm{~m}$, The inclination of the Roadbed slope is $\theta=50^{\circ}$, Water depth $h_{w}=2.3 \mathrm{~m}$, Natural Roadbed fill $\gamma=18.7 \mathrm{kN} / \mathrm{m}^{3}$, Internal friction angle $\varphi=25^{\circ}$ Cohesion $c=25 \mathrm{kpa}$. According to the relevant literature and engineering experience Water absorption coefficient of unsaturated soil $k_{u s}=$

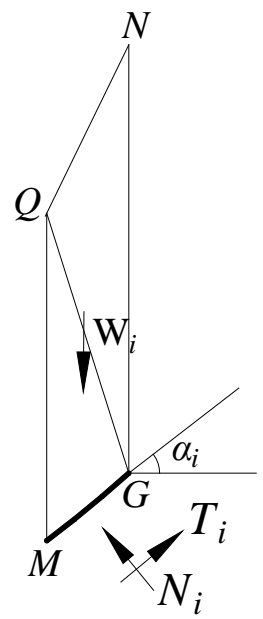

Figure 5. Sketch of the slider force analysis. 
$6.6 \times 10^{-7}$ [8], Coefficient of deterioration of soil parameters $\eta=0.4$ [14], Equivalent Unsaturated Soil Adsorption Strength $\tau_{s}=30 \mathrm{kpa}$. Through the simplified model of roadbed, considering the back pressure of river water, the most unstable slip surface in the natural roadbed can be searched by using the software of geotechnical software. As shown in Figure 6, the center coordinates $O(0.12$, 7.24) is Getd, Radius of circle $R=7.24$, At this time the stability coefficient of natural state is $K=2.126$, it is In a steady state.

Further, the parameters of each block can be derived as shown in Table 1, Since it is difficult to express the coordinates of point $G$ by time $t$ in Equation (7), The form of the function is very complex, here using the inverse analysis method, the continuous function discretization, The time corresponding to point $G(G 0, G 1, \cdots, G i)$ is assumed to be $t 0, t 1 \cdots t i$, and different $G$ points have different Roadbed stability coefficients $\mathrm{K} 0, \mathrm{~K} 1$... Ki, The relationship between the stability coefficient of roadbed and the time $t$ of water penetration is shown in Table 2, and the stability factor is shown in Figure 7. The results show that the stability of the Roadbed will decrease with time when the infiltration and softening of the roadbed are continuous. When the stability coefficient of the Roadbed is 1.05 in the 310 days, it is under steady state. When the stability coefficient is 618 days, $0.97<1$, at this time the roadbed is in an unstable state, prone to subsidence slip failure.

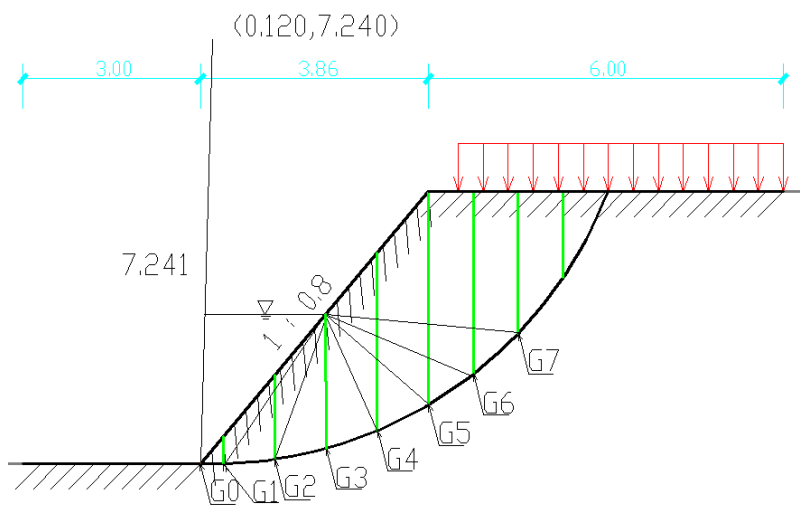

Figure 6. Analysis model of roadbed subsidence.

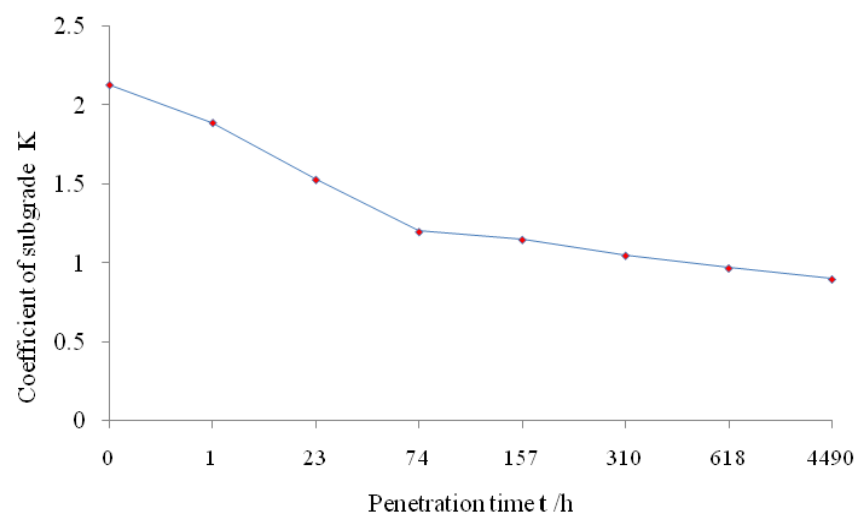

Figure 7. Calculation result of subgrade stability. 
Table 1. Parameters of each block in the Swedish slice method.

\begin{tabular}{cccc}
\hline bar & $\begin{array}{c}\text { The starting horizontal } \\
\text { coordinate of the bar } x_{i}\end{array}$ & Bar Arc length $l_{i} / \mathrm{m}$ & $\begin{array}{c}\text { Border Arc tangent } \\
\text { angle } \alpha_{i} /^{\circ}\end{array}$ \\
\hline 1 & 0 & 0.24 & 0 \\
2 & 0.24 & 0.91 & 4.54 \\
3 & 1.14 & 0.93 & 11.8 \\
4 & 2.05 & 0.96 & 19.25 \\
5 & 2.95 & 1.02 & 27.07 \\
6 & 3.86 & 0.91 & 34.71 \\
7 & 4.61 & 1.02 & 42.35 \\
8 & 5.36 & 1.2 & 51.11 \\
9 & 6.11 & 1.61 & 62.23 \\
\hline
\end{tabular}

Table 2. Calculation results of dynamic stability coefficient of roadbed.

\begin{tabular}{cccccc}
\hline Bar $i$ & $G_{i}$ & $\begin{array}{c}G \text { point } y_{i} \\
\text { coordinate }\end{array}$ & $\begin{array}{c}G \text { point } x_{i} \\
\text { coordinate }\end{array}$ & $\begin{array}{c}\text { Penetration } \\
\text { time } t / \text { day }\end{array}$ & $\begin{array}{c}\text { Dynamic stability } \\
\text { coefficient of } \\
\text { Roadbed } \mathrm{K}_{i}\end{array}$ \\
\hline 1.00 & $\mathrm{G} 0$ & 0.00 & 0.00 & 0.00 & 2.13 \\
2.00 & $\mathrm{G} 1$ & 0.00 & 0.24 & 1.13 & 1.89 \\
3.00 & $\mathrm{G} 2$ & 0.09 & 1.14 & 23.65 & 1.53 \\
4.00 & $\mathrm{G} 3$ & 0.30 & 2.05 & 74.08 & 1.20 \\
5.00 & $\mathrm{G} 4$ & 0.63 & 2.95 & 157.74 & 1.15 \\
6.00 & $\mathrm{G} 5$ & 1.11 & 3.86 & 310.51 & 1.05 \\
7.00 & $\mathrm{G} 6$ & 1.66 & 4.61 & 618.37 & 0.97 \\
8.00 & $\mathrm{G} 7$ & 2.37 & 5.36 & 4490.10 & 0.90 \\
9.00 & $\mathrm{G} 8$ & 3.36 & 6.11 & - & - \\
\hline
\end{tabular}

\section{Conclusions}

1) In this paper, the slip mechanism of the subsidence along the riverbed is qualitatively analyzed both macroscopically and microscopically. It is concluded that the cyclic fluctuation of the river water level and the softening of the embankment soil for a long time are the main predisposing factors.

2) In this paper, based on the simplified Roadbed model, and based on the theory of water absorption in unsaturated soil, a set of calculation formula of dynamic stability coefficient of roadbed is deduced by using Swedish strip method.

3) Through example analysis, the stability of Roadbed will decrease gradually with time, and the stability coefficient of roadbed is 1.05 when it is about 310 days. When the roadbed is under steady state, 618 days, the stability coefficient of $0.97<1$, at this time the roadbed is in an unstable state, prone to subsidence slip failure.

\section{References}

[1] Zhao, Y.K., Li, Q.A., Ren, L.Y. and Re, L.Y. (2008) Study on Stability of Embank- 
ments in Different Immersed Duration of the Lower Yellow River. Yellow River, 30, 13-14.

[2] Tang, X.S., Deng, C.J., Zheng, Y.R. and Wu, X.C. (2008) Study on the Test of Immersed Gravelly Soil Foundation in the Three-Gorges Zone. Chinese Journal of Underground Space and Engineering, 4, 226-229.

[3] He, X.Y., Tang, H.M., Chen, H.K. and Liu, H.D. (2010) Macroscopic Characteristics of Loose Earth in Cyclic Soak at Three Gorges Reservoir Area. Journal of Chongqing Jiaotong University (Natural Science), 3, 445-449, 483.

[4] Deng, X., Huang, Y. and Liu, P. (2013) The Shear Strength Damage-Characteristics of Yunnan Lateritein Soaking Condition. Geotechnical Engineering Technique, 27, 196-200.

[5] Zhang, Z.Q. (2007) Collapsible Loess Roadbed Water Properties Studied. Highway, 1, 44-46.

[6] Li, X., Zhang, L.M. and Fredlund, D.C. (2009) Wetting Front Advancing Column Test for Measuring Unsaturated Hydraulic Conductivity. Canadian Geotechnical Journal, 46, 1431-1445. https://doi.org/10.1139/T09-072

[7] Huang, Y., Shi, J.N., Han, Y.X. and Shi, X.Q. (2010) In-Situ Experimental Study on Water Injection Permeability of Collapsible Loess. Jishu Jiaoliu Yingyong, 11, 31-34.

[8] Li, Y.L., Liu, C.R., Liu, H.N. and Wang, J.H. (2004) Testing Study on Permeability Characteristics of Unsaturated Soil. Chinese Journal of Rock Mechanics and Engineering, 22, 3861-3865.

[9] Liu, W.H. (2013) Under the Condition of Rainfall Infiltration Unsaturated Soil Roadbed Seepage Analysis. Journal of China \& Foreign Highway, 2, 15-18.

[10] Liu, C.H., Chen, C.X., Feng, J.T. and Xiao, G.F. (2005) Effect of Groundwater on Stability of Slopes at Reservoir Bank. Rock and Soil Mechanic, 3, 419-422.

[11] Sun, D.X., Liu, P., Xia, X.H. and Wang, J.H. (2004) Permeability Coefficient of Unsaturated Soils. Journal of Hydraulic Engineering, 3, 71-75.

[12] Burdine, N.T. (1953) Relative Permeability Calculations from Pore Size Distribution Data. Transactions of the American Institute of Mining \& Metallurgical Engineers, 5, 71-78. https://doi.org/10.2118/225-g

[13] Chen, J.Y. and Fredlund, D.G. (2003) Advance in Research on Shear Strength of Unsaturated Soils. 655-660.

[14] Qiao, L., Zhao, Y.K., Li, Q.A. and Li, Q.A. (2008) Predict Stability of Immersed Embankments of the Lower Yellow River. Yellow River, 30, 14-15, 17. 
Submit or recommend next manuscript to SCIRP and we will provide best service for you:

Accepting pre-submission inquiries through Email, Facebook, LinkedIn, Twitter, etc. A wide selection of journals (inclusive of 9 subjects, more than 200 journals)

Providing 24-hour high-quality service

User-friendly online submission system

Fair and swift peer-review system

Efficient typesetting and proofreading procedure

Display of the result of downloads and visits, as well as the number of cited articles Maximum dissemination of your research work

Submit your manuscript at: http://papersubmission.scirp.org/

Or contact gep@scirp.org 